\title{
ANSIEdAde E DEPRESSÃo EM MÃES de CRIANÇAS COM DISTÚRBIOS DE LINGUAGEM: \\ A IMPORTÂNCIA DO TRABALHO INTERDISCIPLINAR
}

\section{Luciane Beltrami; Ana Paula Ramos de Souza ${ }^{\star}$; Luciéle Oliveira Dias}

Universidade Federal de Santa Maria, Santa Maria, RS, Brasil

\section{Resumo}

Este artigo analisa a associação entre os estados emocionais de mães e suas repercussões na interação com seus filhos portadores de distúrbios de linguagem. A metodologia qualitativa abrangeu o estudo de dois casos de crianças com dispraxia verbal e suas mães. A coleta constituiu-se da filmagem das interações das crianças com suas mães, e da avaliação psicológica destas por meio de entrevista e da aplicação da Escala Beck e da técnica projetiva do desenho, casa, árvore e pessoa (H-T-P). Observou-se que em ambos os casos as mães apresentaram niveis de ansiedade e depressão que afetavam o relacionamento delas com seus filhos, o que se refletia no modo como dialogavam com os mesmos, e não favorecia sua evolução linguística. Concluiu-se sobre a importância da clínica interdisciplinar, com participação da psicologia e fonoaudiologia em casos de distúrbios de linguagem para que sejam oferecidos o suporte social e apoio psicológico adequados aos pais para lidarem com o distúrbio de linguagem do filho e também para refletirem sobre o exercício de suas funções parentais.

Palavras-chave: linguagem; avaliação psicológica; interação mãe-filho.

\section{ANXIETY AND DEPRESSION IN MOTHERS OF CHILDREN WITH LANGUAGE DISORDERS: THE IMPORTANCE OF INTERDISCIPLINARY WORK}

\begin{abstract}
This paper analyses the association between mothers emotional states and its repercussion on mother-child with language impairment interactions. The qualitative method was of two cases study verbal dyspraxia children and their mothers. The collection comprised of footage of the interactions of children with theirmothers, and psychological evaluation of these through interview and applying scale Beck and projective technic of draw of house, tree and people (H-T-P). It was noted that in both cases mothers showed levels of anxiety and depression that impacted their relationship with their children, which is reflected in how dialogue with them and not favored their linguistic evolution. It was concluded on the

\footnotetext{
^Endereço para correspondência: Universidade Federal de Santa Maria. Av. Roraima, 1000 Camobi - Santa Maria, RS - Brasil. CEP: 97105-900.E-mail: lucianebeltrami@terra.com.br, ramos1964@uol.com.br, lu_fonoaudiologia@yahoo.com.br.
} 
importance of interdisciplinary clinic, with participation of psychology and speech therapy in cases of language disorders to be offered appropriate social and psychological support to parents to cope with the child language disorder and also to reflect on the exercise of their family roles.

Keywords: language; psychological assessment; mother-child interaction.

\section{INTRODUÇÃo}

Além das predisposições genéticas da criança, enfatizadas nas pesquisas dos distúrbios de linguagem, a relação mãe-filho é outro aspecto a ser considerado na análise dos distúrbios de linguagem, uma vez que a mesma é a base de toda a estruturação psíquica e constituição linguística infantil, podendo influenciar, positivamente ou não, na expressão genética. A fala excessiva da mãe ou as ausências desta no diálogo com seus filhos podem criar obstáculos ao funcionamento da linguagem infantil, uma vez que, desse modo, as mães não proporcionam o espaço necessário para que a criança sinta desejo em falar ou mesmo para que possa concretizá-lo, superando possíveis limitações orgânicas (RECHIA; SOUZA, 2010). Isso porque é grande a influência da mãe e/ou cuidador no desenvolvimento neurobiológico e psicológico da criança (MOTTA, 2005).

Alguns autores observaram que o diálogo mãe-filho assume características singulares influenciadas tanto por fatores relacionados ao exercício da função materna (RECHIA; SOUZA, 2010; CRESTANI et al., 2012) quanto por limitações biológicas do filho como a dispraxia verbal, um distúrbio de linguagem que pode gerar grande ininteligibilidade de fala, pelas inúmeras alterações articulatórias que produz, o que pode dificultar muito a comunicação mãe-filho (RECHIA et al., 2009, 2010).

Tais dificuldades podem relacionar-se, também, ao fato de que familiares de crianças com dificuldades de linguagem demonstram sentimentos de culpa que podem paralisá-los e deixá-los impotentes para lidar com a limitação do filho (LEMOS; BARROS; AMORIM, 2006). Além disso, crenças inadequadas dos pais acerca de seus filhos podem exacerbar os níveis de ansiedade e depressão dos pais. Mesmo em situação típica de aquisição da linguagem, os desafios das novas aquisições infantis trazem sentimentos ambíguos de gratificação e realização, convivendo com sentimentos de maior demanda e dedicação (LOPES et al., 2007).

A ansiedade, assim como a maioria dos sintomas psíquicos, é determinada por aspectos múltiplos, derivados de uma variedade de níveis de desenvolvimento. Freud a conceituou, tanto como uma manifestação sintomática do conflito neurótico, quanto como um sinal adaptativo para afastar esse conflito da consciência. Assim, a ansiedade funciona como um alerta que possibilita à pessoa tomar medidas para lidar com a ameaça subjacente à situação de perigo, ou seja, a ansiedade normal é uma reação necessária do organismo, tendo como finalidade protegê-lo ou criar reação a qualquer estímulo, que demande ficar alerta e com atenção aumentada. Porém, quando a ansiedade ocorre de forma exacerbada, desproporcional à situação que a desencadeou, e de modo contínuo, ela é patológica, 
pois desgasta o sujeito, que fica constantemente se defendendo, tornando-o incapacitado orgânica, psicológica, social e profissionalmente (GABBARD, 2006; CORREIA; LINHARES, 2007).

A ansiedade-estado está ligada a um momento, evento ou situação particular, como a descoberta de um distúrbio ou doença na família, ou no filho, causando um estado emocional transitório (FERREIRA et al., 2009). Já a ansiedade-traço está relacionada a características individuais de personalidade, que manifestam disposições diferentes entre os indivíduos na maneira de encarar as situações ansiogênicas (FERREIRA et al., 2009). Salienta-se que esses fatores ansiogênicos podem interferir negativamente sobre alguns aspectos cognitivos, como o processo de aprendizagem, a redução de atenção e da concentração, diminuindo, dessa forma, a aquisição de habilidades (FERREIRA et al., 2009; CONDE; FIGUEIREDO, 2005). Assim, a ansiedade em exagero pode explanar a falta de foco adequado no diálogo da mãe enquanto interlocutora do filho.

A avaliação da ansiedade pode ser feita por meio de escalas como a Spielberger State-Trait Anxiety Inventory (STAIT), Escala Hospitalar de Ansiedade e Depressão (HAD), Escala de Hamilton de Ansiedade, Inventário de Ansiedade Traço-Estado (IDATE) e Inventário de Ansiedade de Beck (BAI) (FERREIRA et al., 2009).

Em muitos casos, a ansiedade coocorre com a depressão, sendo esta uma alteração do estado de humor, com predomínio anormal da tristeza. Na depressão nem sempre é possível haver clareza sobre quais acontecimentos da vida levaram a pessoa a ficar deprimida, diferentemente das reações depressivas normais e das reações de ajustamento depressivo, nas quais é possível localizar o evento desencadeador. Assim, as causas de depressão são múltipla desde questões constitucionais da pessoa - fatores genético, neuroquímicos, ambientais, sociais e psicológicos, como também, a existência de doença na família (ZUCCHI, 1999). A avaliação da depressão pode ser feita através de escalas, como a Escala Beck e a Escala Hamilton. Vários estudos demonstram que a depressão é duas vezes mais frequente em mulheres do que em homens (COUTO et al., 2009; PINTO et al., 2009; FRIZZO et al., 2010).

No grupo de pesquisa ao qual pertence este trabalho alguns estudos já demonstraram que tanto a ansiedade quanto a depressão estão correlacionados estatisticamente com a presença de risco ao desenvolvimento infantil (FLORES et al., no prelo; PRETTO-CARLESSO e SOUZA, 2011).

A partir das considerações a respeito de que mães ansiosas podem protagonizar interações que não favorecem o desenvolvimento de seus filhos, este estudo de casos buscou analisar os resultados da avaliação psicológica de duas mães de crianças com dispraxia verbal e relacioná-la ao que foi observado nas interações com seus filhos, sobretudo no diálogo, durante a intervenção fonoaudiológica. 


\section{Metodologia}

Esta pesquisa é do tipo qualitativa e de estudo de caso. Participaram dela duas crianças com dispraxia verbal e suas mães. As famílias buscaram a clínica-escola fonoaudiológica, em função de as crianças falarem pouco e de modo pouco inteligível.

A coleta de dados acerca do histórico das crianças e das interações das mães com seus filhos foi realizada a partir da consulta aos prontuários das mesmas, e a um banco de dados de imagens, no qual se encontravam as filmagens das mães com as crianças, antes, durante e após intervenção fonoaudiológica de concepção interacionista, realizadas nos trabalhos de Rechia e Souza (2010), Rechia et al. (2009, 2010), e Crestani et. al.(2012). Ressalta-se que a filmagem da interação entre as mães e seus filhos foi realizada em situação lúdica, utilizando-se brinquedos temáticos (carrinhos, casinha, bonecas, panelinhas, animais, entre outros), colocados à disposição para que a criança pudesse fazer sua escolha. Foram filmados aproximadamente 30 minutos de cada criança com sua mãe.

Dessas filmagens e dos prontuários foram selecionados dados nos quais foram observados o diálogo mãe-filho quanto à distribuição de turnos, extensão dos enunciados maternos e as posições discursivas ocupadas pelas crianças a partir do deslocamento da perspectiva interacionista para a análise dos distúrbios de linguagem (LEMOS, 1992), ou seja: buscou-se observar como estava ocorrendo o funcionamento de linguagem em termos de processos metafóricos e metonímicos, considerando os enunciados da criança e do adulto.

Com as mães foram realizadas entrevistas continuadas, nas quais havia a participação de uma fonoaudióloga e de uma psicóloga. Posteriormente, foi realizada uma entrevista individual por uma psicóloga, na qual foram coletadas informações gerais sobre sua vida, sua experiência da maternidade, e a aplicação do Inventário de Ansiedade de Beck (BAI) e Inventário de Depressão de Beck (BDI) (BECK; STEER, 1993) e H-T-P- técnica projetiva do desenho de casa-árvore-pessoa (BUCK, 2003).

A Escala Beck objetiva uma rápida avaliação de estados de humor, sendo apropriada para pacientes na faixa de 17 a 80 anos de idade, e pode ser usada em sujeitos sem transtornos psiquiátricos. Ela é constituída do Inventário de Ansiedade de Beck (BAI) e do Inventário de Depressão de Beck (BDI) (BECK; STEER, 1993).

O BAI (BECK; STEER, 1993) foi construído com base em vários instrumentos de autorrelato, e mede a intensidade de sintomas de ansiedade. Foi adaptado e validado para o Brasil por Cunha (2001) e é constituído por 21 itens, que são afirmações descritivas de sintomas de ansiedade e que devem ser avaliados pelo sujeito com referência a si mesmo, em uma escala de 4 pontos, que reflete o nível crescente de cada sintoma desde a não presença de sintomas até a presença de sintomas graves. O escore total é o resultado do escore dos itens individuais e permite a classificação em níveis de intensidade da ansiedade: mínimo ( 0 a 10), leve ( 11 a 19), moderado (20 a 30) e grave ( 31 a 63). É considerada ansieda- 
de clinicamente importante a partir do estágio leve. Especificamente em relação à ansiedade ela testa consequências fisiológicas (tremor, sudorese, dor abdominal...) e psíquicas (medo, insegurança...) em uma escala que vai desde a ausência até a impossibilidade de suportar determinado estado. Quanto ao tempo de aplicação, estima-se de 5 a 10 minutos para a forma auto-administrativa (individual ou em grupo) e de 10 minutos em média, para a aplicação oral.

O BDI (BECK; STEER, 1993) consiste de um questionário de autorrelato com 21 itens de múltipla escolha. É um dos instrumentos mais utilizados para medir a severidade de episódios depressivos. Seu desenvolvimento marcou uma mudança entre os profissionais de saúde mental, que até então entendiam a depressão em uma perspectiva psicodinâmica, ao invés de enraizada nos próprios pensamentos dos pacientes (cognição). Na versão atual, o questionário é desenhado para pacientes acima de 13 anos de idade e é composto de diversos ítens relacionados aos sintomas depressivos como desesperança, irritabilidade e cognições como culpa ou sentimentos de estar sendo punido, assim como sintomas físicos como fadiga, perda de peso e diminuição da libido. A escala é largamente utilizada como ferramenta para medida por profissionais de saúde e pesquisadores em uma variedade de contextos clínicos e de pesquisa (BECK; STEER, 1993).

O H-T-P - Técnica projetiva de desenho - casa - árvore - pessoa - estimula a projeção de elementos da personalidade e de áreas de conflito, podendo obter informações sobre como o examinado vive sua individualidade em relação aos outros e ao ambiente do lar. Pode ser aplicado em sujeitos acima de 8 anos de idade (BUCK, 2003).

Após a avaliação das mães, seus dados foram confrontados qualitativamente com o histórico fonoaudiológico de seus filhos.

\section{ApresentaÇão dos Casos}

\section{Caso 1}

\section{Histórico terapêutico e interações mãe-filha}

Trata-se de uma díade formada por MP, uma menina, que iniciou tratamento fonoaudiológico no ano de 2007, em função de falar pouco e de modo ininteligível. Após uma pausa na terapia que se extendeu do segundo semestre de 2008 ao segundo semestre de 2009, ela retornou à terapia fonoaudiológica com queixas de trocas na fala, com a idade de 6 anos.

Em relação ao histórico gestacional, a mãe (MMP) afirmou que a gravidez não foi planejada e que ocorreu quando ela estava com apenas 20 anos. Tal período foi acompanhado de vômitos, enjôos e muito nervosismo, sendo que a partir do oitavo mês apresentou hipertensão arterial. O parto foi a termo, cesárea. MP nasceu com 4.095 quilos e 50 centímetros. Chorou logo. A reação dos familiares ao nascimento de MP foi de grande alegria. 
A menina foi amamentada até os 2 anos e 7 meses, parando apenas porque viu sua irmã mais nova começar a mamar e perdeu o interesse. Utiliza mamadeira até hoje, mas nunca usou chupeta. A alimentação sólida iniciou aos 6 meses, e atualmente come todo o tipo de consistência e tempero alimentar. A dentição iniciou aos 4 meses. Quanto ao sono, sempre foi agitado desde o nascimento, às vezes roncava e apresentava cialorréia. Em relação ao desenvolvimento neuropsicomotor houve uma boa evolução, não apresentando dispraxia corporal. $\mathrm{O}$ controle de esfíncteres ocorreu sem intercorrências.

Em relação à linguagem, MP balbuciou aos 6 meses, disse as primeiras palavras aos 8 meses, mas frases simples só após as primeiras orientações fonoaudiológicas recebidas em atendimentos realizados em Unidade Básica de Saúde, quando estava com 3 anos. Naquela ocasião foi encaminhada ao serviço da clínica-escola. Para se comunicar utilizava gestos, quando não era compreendida. Em geral, somente a família, pais e avós a compreendiam, o que causava irritação em MP quando diante de outros interlocutores.

Quanto a aspectos gerais de saúde, apresentou episódios de alergia de pele, asma, bronquite e rinite. Seus exames auditivos apresentaram resultados normais, apesar de um episódio de otite média na orelha esquerda.

Em relação a antecedentes familiares, a avó paterna apresenta transtornos neurológicos e quadro depressivo. Além disso, a família paterna apresenta problemas de visão e de fala, sendo que o pai passou a falar bem apenas com 7 anos, e ainda falava com dificuldade a época da pesquisa, na percepção da mãe.

No relato do caso feito por Rechia et al.(2009), a autora afirma que, embora MP falasse, não evoluía na sua fala de modo compatível com sua faixa etária em função da presença de dispraxia verbal. Observava-se a dificuldade de a mãe promover a passagem de MP da dependência absoluta para a dependência relativa, pois embora a fonoaudióloga houvesse orientado a retirada de MP do quarto dos pais, a mãe não sustentava tal ação, retirando a menina do mesmo por alguns dias, mas retornando a seguir.

Em termos de diálogo, a mãe (MMP) conseguia responder de modo adequado ao que a filha solicitava, mas ocupava seus turnos de modo extenso, sem permitir que a menina pudesse falar ou mesmo responder a seus questionamentos, conforme se vê na sequência 1, na qual MP e sua mãe (MMP) dialogam:

\section{Sequência 1}

1. MP: tuto bem tilhinha ta bem (tudo bem filhinha, tá bem ?)

2. MMP vamo lê um livrinho pra ela?

3. MMP: traz tua filhinha aqui.

4. MP: eu vou botar ela aí, ela ta domindo

5. MMP: tem que arrumar direitinho.

(...) 
6. MMP: A bela e a fera, ariel...

7. MP: Ariel

8. MMP: o Aladim, o Bambi. Tu lembra, essa historinha tu tinha ó.

9. MMP: ó o patinho feio. Eu não to achando o Pinóquio.

10. MP: Queio Pinoyu (quero Pinóquio).

(...)

11. MP: Ele ta uma toida pa pa pa mim (ele trás uma coisa pra mim)

12. MMP: é.

Após a intervenção terapêutica, que incluiu tanto os atendimentos fonoaudiológicos individuais de MP, quanto a realização de entrevistas continuadas com sua mãe, houve uma melhora, tanto na fala de MP, quanto na postura de sua mãe durante o diálogo. A proposta terapêutica foi de concepção interacionista, tendo o brincar temático como base das ações com MP em sessões individuais e conjuntas com a mãe. Como MMP se apresentava muito ansiosa, priorizou-se a realização de sessões individuais da menina com a terapeuta, pois se percebeu que era o desejo de MP.

No segundo semestre de 2009, MP recebeu atendimento terapêutico grupal, com mais duas meninas. Observava-se que ela tomava o turno e apresentava, com os interlocutores, a mesma característica ansiosa da fala da mãe com ela, observada no primeiro período de intervenção.

Em abril de 2010, MP compareceu novamente à clínica-escola para dar continuidade a terapia. A menina ainda produzia de modo inadequado vários fonemas e estruturas silábicas, demonstrando limitações fonológicas. Tais trocas na fala de MP ocasionavam confusões na escola, pois algumas palavras soavam como "palavrão". Em relação ao rendimento escolar, MP está cursando a $1^{\text {a }}$ série $\left(2^{\circ}\right.$ ano) e estava com dificuldades de concentração. A professora chamava a sua atenção e ela ficava brava.

MP manteve-se na terapia fonoaudiológica até 2012, embora com algumas trocas, mas a fala apresentava-se bem mais inteligível. Em 2012, MP atingiu a hipótese alfabética na escrita e passou a ler e escrever palavras e pequenas frases, progresso esperado para o final do segundo ano do primeiro ciclo escolar. MP continuará a terapia em 2013 com possibilidades claras de alta fonoaudiológica nessa etapa.

\section{Resultados da avaliação da mãe de MP}

A mãe de MP, com 26 anos à época desta coleta, tinha ensino médio completo e técnico em contabilidade. Frequentava sua igreja no mínimo cinco vezes por semana, em companhia de seus pais, marido e filhas. É a primogênita tendo mais dois irmãos, na ocasião adolescentes. 
Após entrevista inicial, iniciou-se a avaliação psicológica, com aplicação das escalas de Beck (BECK; STEER, 1993) para ansiedade e depressão. O nível de ansiedade resultou grave e o de depressão moderado. O H-T-P (BUCK, 2003) também refletiu ansiedade e depressão, o que pode justificar o resultado alto na Escala Beck. A mãe de MP demonstrou sentimento de inadequação e insegurança, necessitando de apoio. No lar, evidenciava, em seu discurso, falta de calor afetivo e presença de ambiente tenso, o que a levava a tomar atitudes defensivas e buscar o isolamento. Comentava que se sentia sozinha e que o marido não a ajudava em nada nos afazeres de casa e com as filhas. Sentia falta de suporte social adequado para se sentir segura e acolhida. Trabalhava fora antes de ter as filhas, fazia faxinas, e, na época da entrevista, fazia trabalhos manuais e vendas como autônoma, porém não se sentia realizada.

Quando as filhas cresceram, procurou emprego fixo, mas acredita que não conseguiu porque as pessoas têm preconceito em relação a sua obesidade, o que trouxe a sensação de rejeição e tristeza.

A avaliação psicológica da mãe confirmou a dificuldade da família em tratar MP de modo adequado para a sua idade. Houve demora em retirar as fraldas e sustentar a separação entre MP e a mãe, pois a mesma permaneceu por longo período no quarto dos pais. Percebeu-se, nos relatos da mãe, a falta da função paterna, para fazer o corte necessário na simbiose entre ela e a filha.

A mãe fez alguns cursos técnicos e quer terminar outro. Pretende trabalhar na área da saúde cuidando de pessoas. Porém, no momento sente-se esgotada e insatisfeita com a sua vida, dizendo: "Não sou realizada como pessoa, tinha outros planos para mim... terminar técnico...mas engravidei..."

A fala e a expressão da mãe de MP são de uma pessoa cansada da rotina de dona de casa e mãe, sem privacidade para si, como mulher e esposa. No entanto, viu que poderia conseguir tempo para isso organizando-se, ou seja, também se colocando como prioridade, sem descuidar do papel materno, o que ajudaria na sua autoestima e satisfação pessoal. Percebeu-se que, para que isso ocorresse, seria conveniente que participasse do grupo de pais ou fizesse psicoterapia individual, pois sua insatisfação refletia na família de forma negativa, e acabava culpando-se pela dificuldade de fala da filha. Embora tivesse momentos de consciência acerca das dificuldades da relação familiar, persistia em tomar atitudes que infantilizam a filha como dar mamadeira.

\section{Caso 2}

\section{Histórico terapêutico e interações mãe-filho}

LVO, um menino de 4 anos e 4 meses, foi trazido à clínica-escola em abril de 2009, por sua mãe, com queixa de falar pouco. A gravidez de LVO não foi planejada, mas bem aceita e ocorreu quando a mãe tinha 20 anos de idade. $\mathrm{O}$ período gestacional foi tranquilo, acompanhado de felicidade e expectativas de um bebê saudável. O parto foi pré-termo e tipo cesárea. LVO nasceu com 2.430 quilos e 50 centímetros, roxo e demorou para chorar. A reação dos familiares foi 
de preocupação, pois o menino apresentava quadro de sindactilia. LVO foi amamentado até 1 ano, parando naturalmente. Não utiliza mamadeira, nem chupeta. A alimentação sólida iniciou aos 6 meses, e atualmente é seletivo com os alimentos, preferindo carnes a legumes. A dentição iniciou aos 7 meses.

Quanto ao sono, era calmo até o seu primeiro ano. Ao início da terapia era agitado, apresentava respiração oral e cialorréia. LVO dormia no quarto com os pais porque não havia outro quarto na casa, embora os pais estivessem providenciando a construção do mesmo. A mãe percebia que quando este assunto surgia, o menino ficava um pouco ansioso.

Em relação ao desenvolvimento neuropsicomotor, ocorreu com leve atraso, em decorrência de recuperação cirúrgica no pé (sindactilia). LVO já controlava os esfíncteres quando chegou ao atendimento fonoaudiológico. Em relação à linguagem, balbuciou aos 8 meses, disse as primeiras palavras com 1 ano e 6 meses, e as primeiras frases aproximadamente aos 3 anos. Para se comunicar, usava gestos, pois somente as pessoas mais próximas da família, entendiam sua fala, o que causava cobranças dos demais familiares sobre o desenvolvimento do menino. A mãe afirmava ter dúvidas sobre as causas desse atraso e sentia-se incomodada em relação à dificuldade do filho. Tais dúvidas foram esclarecidas durante a realização de grupo operativo com pais de várias crianças com distúrbio de linguagem, realizado com fonoaudióloga e psicóloga, o que parece ter diminuído a ansiedade e a culpa desta mãe e dos demais pais sobre as origens de distúrbios como a dispraxia verbal e outros problemas de linguagem.

Quanto às atividades diárias, o paciente necessitava de auxílio, principalmente da mãe, com quem era mais ligado. O menino apresentava humor variável, costumava apresentar crises de birra e reagia gritando quando contrariado. Segundo a mãe, convivia mais com adultos e crianças maiores.

Quanto a antecedentes fisiopatológicos, o menino apresentou febre alta em decorrência de infecção intestinal, fez correção de sindactilia aos 6 anos e 11 meses e aos 2 anos. Em relação aos antecedentes familiares maternos há casos de depressão e nervosismo, pois esta afirmava possuir tios com síndrome do pânico. Em relação aos paternos, sabe-se que o pai iniciou a fala tardiamente, aos 4 anos.

A fonoaudióloga percebia a ansiedade da mãe (MLVO) que, durante a primeira filmagem com o filho apresentou dificuldades de entregar-se ao brincar e de dialogar com o mesmo. Limitou-se a nomear alguns objetos e a arrumá-los sobre a mesa, sem estabelecer um brincar propriamente dito, como pode ser visto na Sequência 2:

\section{Sequência 2}

Mãe e filho pegam animais de dentro de uma caixa de madeira. A mãe regula o comportamento do menino solicitando que faça a volta e pegue a caixa e o ajuda a se sentar na cadeira.

Começam a retirar os animais. A mãe (MLVO) retira um a um e dá a LVO. que os coloca de modo arrumado em cima da mesa, com a ajuda da mãe. 
LVO. tira um brinquedo e enuncia algo ininteligível

MLVO: - E esse o que são?

- um cavalo ! (em tom ascendente)

LVO.-é aqui!

MLVO: pega objeto e pergunta: - O que é esse?

LVO: ele olha sem responder e arruma o objeto na mesa

LVO: Depois pega outro animal e enuncia: - esse.

MLVO: - Esse pequenininho.

MLVO: Em relação a outro pergunta: - O que é isso? Cavalo!

LVO: - Essa vaca.

MLVO: - Vaca?

LVO: Fala ininteligível

MLVO: - Tu gosto?

LVO: - Hum! (em tom afirmativo)

LVO demonstrava, nas sessões com a terapeuta, poder articular cenas e atingir níveis mais evoluídos na capacidade representacional, mas isso não emergia na interação com a mãe, como se observou no exemplo anterior.

A intervenção fonoaudiológica individual com LVO pautou-se no brincar temático, com estratégias como espelhamento e espelhamento diferido de modo a aumentar a extensão e aprimorar articulatoriamente os enunciados de LVO. O menino demonstrou-se atento e motivado para dialogar e melhorar sua fala na interação com a terapeuta. Buscava espelhar a fala da mesma, aprimorando a própria fala. Seu brincar ficou mais complexo, atingindo a possibilidade do faz de conta. Passou, após quatro meses de terapia, a ocupar a posição de falante/ ouvinte, corrigindo-se ao perceber que produzia enunciados incorretos. Adquiriu praticamente todos os contrastes fonológicos, restando apenas as líquidas não-laterais para aquisição ao final de 2009, o que era esperado, tendo em vista a alta complexidade dessas consoantes que são mais tardias na aquisição fonológica.

A mãe, a partir das orientações grupais e também da percepção da evolução do filho, melhorou tanto no brincar quanto no diálogo com o mesmo. Passou a conferir-lhe mais turnos, escutando-o mais e entregando-se mais ao brincar, sobretudo nos momentos de faz de conta.

LVO retomou a terapia fonoaudiológica em março de 2010. Na época, percebeu-se que, apesar da melhora do menino e diminuição da ansiedade materna, a mãe continuava com dificuldades para promover a maior independização do mesmo e também para sustentar o ingresso do menino na escola. Em função disso, a fonoaudióloga encaminhou a mãe para trabalho individual com a psicóloga. 
O trabalho psicológico iniciou no mês de maio, quando LVO ingressou na escola. Sua adaptação, segundo a pedagoga que orientou a mesma, foi excelente, embora a mãe sentisse muita apreensão em deixá-lo na escola, acreditava que a primeira semana foi mais "difícil para ela do que para o filho." Percebeu-se, naquele momento, que a indicação do suporte psicológico para a mãe foi fundamental para que a mesma sustentasse a ida de LVO para a escola, pois esteve a ponto de desistir.

A mãe foi muito receptiva e participativa nas sessões de avaliação psicológica, cujo resultado das escalas BDI e BAI (BECK; STEER, 1993) foram de leves traços de depressão e ansiedade. No H-T-P (BUCK, 2003) evidenciou-se descontentamento, insegurança e ansiedade. Revela contato pobre com a realidade, fragilidade e preocupação com o ambiente, antecipando-se ao futuro. A mãe de LVO demonstra rigidez e retraimento de forma exacerbada o que pode explicar suas dificuldades de interação com o filho.

A partir dos resultados dessa avaliação, foi possível justificar para a mãe a necessidade de a mesma receber atendimento psicológico. Sua adesão ao atendimento foi imediata e, já nas primeiras sessões, demonstrou progressos na relação familiar. Conseguiu sustentar a ida de LVO para a escola, organizou quarto do menino e retomou alguns planejamentos seus, durante o turno em que o filho estava na escola. Afirmava também que sua vida com o esposo (que é militar) melhorou muito, pois, enquanto LVO estava na escola, possuiam momentos mais íntimos em que podiam conversar e namorar sem se preocupar em dar atenção ao filho.

\section{Discussão}

A análise dos casos apresentados neste estudo demonstra que a avaliação e a intervenção psicológicas junto aos pais constituem-se espaço importante durante a terapia de crianças com distúrbios de linguagem. Em ambos os casos, detectou-se a presença de ansiedade e depressão maternas que possuiam efeitos importantes na relação mãe-filho (GABBARD, 2006; CORREIA; LINHARES, 2007; COUTO et al., 2009; PINTO et al., 2009; FRIZZO, 2010).

Além disso, o fato de ambas as mães terem tido filhos ainda muito jovens e de modo não planejado, criou dificuldades na rede de apoio no período pós-parto. Ambos os pais, demonstraram dificuldades em proporcionar o corte necessário na simbiose mãe-filho, sobretudo no caso de MP. A função paterna, assim como a materna, é responsável por introduzir o bebê no mundo do simbólico. Sabe-se que não necessariamente são cumpridas pela mãe e pai biológicos, mas é importante que alguém as ocupe durante a constituição psíquica do bebê.

É a função paterna que trará à criança certa estabilização psíquica, devido a um trabalho de enodamento dos três registros que ele lhe oferece: a) uma simbolização da falta, b) uma resposta ao real da angústia de castração e c)uma contenção imaginária para o corpo. Quando o pai (ou aquele que exerce esta função) está presente, a sua participação como mediador da interação mãe-bebê, pode ter uma influência direta sobre o desenvolvimento da criança (KUPFER; BERNARDINO, 2009). 
Para que isso se dê, é necessário que o desejo da mãe seja interditado para que a criança não fique aprisionada a responder como objeto da mãe. Se a criança representa o objeto que satura o desejo da mãe, não haverá lugar para que uma interrogação pelo desejo seja formulada. A função paterna lembra à mãe que seu bebê é um sujeito diferente dela e do qual ela não tem posse absoluta, o que permite a ela ver que há no bebê desejos diferentes dos seus (BERNARDINO, 2008).

Nos casos estudados, o corte da simbiose mãe-filho, seja pelo pai real, ou por alguém que cumprisse esta função, não ocorreu plenamente, impossibilitando o processo de mudança natural pelo qual a função materna deve passar para que a criança continue sua evolução da dependência absoluta para a independência (WINNICOTT, 2000). Alguns autores (NUNES; FERNANDES; VIEIRA, 2007) evidenciaram que a ausência da função paterna pode trazer consequências negativas para a mulher, desde a forma como vive a gestação, até a maternidade. Verifica-se que a deficiência de uma figura paterna pode ser o gatilho para o aparecimento de sintomas ansiosos e depressivos nas puérperas e, consequentemente, para o desenvolvimento mal-adaptativo do bebê. Diante disso, fica evidente o importante papel que a função paterna assume no desenvolvimento saudável do bebê e dos outros filhos, e no restabelecimento da esposa/mãe, revelando a influência do comportamento parental, não só para o bebê, como para seus irmãos e como suporte para a mãe. Os dois casos são uma evidência dessa importância da articulação das funções parentais e demonstram também que, embora houvesse limitações biológicas para a aquisição da linguagem das crianças, o fonoaudiólogo que tem uma perspectiva interdisciplinar, ao socorrer-se da intervenção do profissional psicólogo, pode impedir que outros sintomas se perpetuem no desenvolvimento infantil. É evidente que ambas as crianças estavam em risco quanto à sua adaptação social, sobretudo escolar e que a intervenção da psicóloga teve efeitos importantes nesse aspecto, em especial no caso de LVO em que os efeitos podem ser sentidos na família, não só na relação dos pais com o filho, como na do casal. Possivelmente, este caso foi mais bem sucedido porque o pai pode ocupar sua função e sustentar o corte necessário junto à díade mãe-filho.

Em relação à ansiedade, sabe-se que a mesma tem sido mais investigada no período pré-natal (FAISAL-CURY; MENEZES, 2006). No entanto, os casos aqui apresentados demonstram que pode ser considerado importante fator de risco no período pós-natal. Esse fato é reforçado por estudos que afirmam que na fase do puerpério, aumentam os riscos de transtornos em face das preocupações, anseios e planejamentos realizados e sentidos pela mulher (SILVA, 2005). Flores et al. (no prelo) encontraram ainda, associação combinada dos dois estados de humor (depressão e ansiedade) e presença de risco ao desenvolvimento. Considerando que a autora utilizou os Índices de Risco ao Desenvolvimento Infantil de Kupfer (2008) e que os mesmos se relacionam a protoconversação inicial não é difícil perceber como a ausência de tais índices pode ter interferido na presença de limitações importantes no diálogo mãe-filho(a) nos casos estudados.

Além disso, no puerpério, ocorre maior probabilidade de conflitos na interação mãe e filho, decorrentes da vivência da maternidade pela mãe, que podem variar desde a ansiedade de adequações à nova realidade situacional até distúr- 
bios do humor, que vão da melancolia, às psicoses puerperais. A maternidade marca uma nova fase na vida da mulher. Representa uma transição que faz parte do processo normal do desenvolvimento, envolvendo uma mudança de identidade e uma nova definição de papel. A gestante, além de filha e mulher, passa a ser mãe. Porém, quando a vida começa diferente, como no caso da prematuridade de LVO, esse processo normal de transição torna-se frágil necessitando de cuidados para a mãe e para o bebê (WINNICOTT, 2000).

De acordo com Lopes et al. (2007), a ansiedade é capaz de influenciar a vivência da gravidez, do parto e da adaptação entre mãe-filho, pois aumenta o risco de experiências negativas, sendo fonte de muitas fantasias. Isto requer intervenção especializada, principalmente em relação às repercussões nas futuras interações sociais da criança.

As características maternas e dos bebês podem dificultar ou inviabilizar essa interação inicial (PRADO; PIOVANOTTI; VIEIRA, 2007; CID; MATSUKURA; SILVA, 2007). As mães com transtorno de humor são menos satisfeitas com o suporte social que recebem, punem mais de forma inconsistente seus filhos e possuem estilo parental considerado de risco para o desenvolvimento de comportamentos antissociais nas crianças. Quanto menor o nível de satisfação das mães em relação ao suporte social, mais elas utilizam práticas parentais negativas e mais as crianças apresentam dificuldades (CID; MATSUKURA; SILVA, 2007; MIAN et al., 2009). Pôde-se observar, nas interações das mães de MP e LVO, que havia influência dos estados ansiosos e depressivos das mesmas. Ambas apresentavam dificuldade para brincar e dialogar de modo fluido e prazeroso com os filhos. Esse fato era sentido pelas crianças que preferiam ficar a sós com as fonoaudiólogas que as atendiam do que em companhia das mães.

Somava-se a predisposição genética para o distúrbio de linguagem em ambas as crianças, com claro fator hereditário, pois, ambos os pais foram falantes tardios e possivelmente com distúrbios de linguagem, as dificuldades relacionais com os seus filhos (BUIZA-NAVARRETE; ADRIAN-TORRES; GONZÁLEZ-SÁNCHEZ, 2007). A presença de um exercício das funções parentais frágeis, tanto em função dos sintomas ansiosos e depressivos das mães, quanto em função da dificuldade da função paterna se fazer presente. Ambos os casais não haviam planejado o nascimento das crianças e pareciam estar pouco preparados para assumir as funções parentais, o que parece ter criado uma situação complexa para o desenvolvimento das mesmas. Em meio a essa situação, a evolução de linguagem das crianças correu riscos adicionais aos fatores genéticos e demonstrou que a terapia fonoaudiológica necessita incluir um trabalho continuado com os pais, motivando-os para a busca de sua própria terapia, quando o exercício das funções parentais estiver comprometido (SOUZA; KLINGER; MALDANER, 2009).

Em ambos os casos estudados, as mães foram motivadas e aderiram à terapia psicológica. A mãe de LVO fez uma adesão maior, o que, em conjunto com seu menor comprometimento, levou ao maior progresso da situação do filho, tanto em termos de desenvolvimento linguístico, quanto de inserção escolar. Já a mãe de MP, com distúrbio de humor mais grave e com menor participação, tanto 
na atividade grupal disposta em 2009, quanto na presença ao atendimento psicológico( o que se deu mais recentemente) arca com as consequências familiares de tal demora no acesso e adesão à terapia psicológica.

\section{CONSIDERAÇõES FINAIS}

A partir da análise dos resultados da avaliação psicológica de duas mães de crianças com distúrbio de linguagem, pode-se observar que a ansiedade e a depressão eram sintomas importantes nos casos investigados. Elas tiveram efeitos importantes no exercício das funções maternas, que, somados à predisposição genética para o distúrbio de linguagem das crianças, e às dificuldades no exercício da função paterna, tornava mais complexa sua evolução tanto em termos de socialização quanto de linguagem. A intervenção terapêutica foi bem sucedida na medida em que os pais, sobretudo as mães, aceitaram a intervenção do profissional de psicologia, pois as evoluções de linguagem, sobretudo na fala que se tornou compreensível, puderam ser acompanhadas e influenciadas pelas mudanças familiares e consequente inserção escolar. O presente estudo demonstrou a importância de uma atuação interdisciplinar entre psicologia e fonoaudiologia nos distúrbios de linguagem.

\section{REFERÊNCIAS}

BECK, A. T.; STEER, R.A. Beck Depression Inventory Manual. San Antonio: Psychological Corporation, 1993.

BERNARDINO, L. Aspectos psíquicos do desenvolvimento infantil. In: WANDERLEY, D. B. O cravo e a rosa - a Psicanálise e a Pediatria: um diálogo possível? Salvador: Ágalma, 2008. p. 54-66.

BUCK, J. N. H-T-P Casa-árvore-pessoa, técnica projetiva de desenho: manual e guia de interpretação. São Paulo: Vetor; 2003.

BUIZA-NAVARRETE, J. J.;ADRIAN-TORRES, J.A.; GONZÁLEZ-SÁNCHES, M. Marcadores neurocognitivos em el transtrono específico del lenguaje. Revista de Neurologia, Barcelona, v. 44, n. 6, p. 326-333, jan./jun. 2007.

CID, M. F. B.; MATSUKURA, T. S.; SILVA, M. D. P. O impacto da saúde mental materna: estilo parental, suporte social e desenvolvimento sócio-emocional dos filhos. CoPG - Congresso de Pós-Graduação e $7^{\mathrm{a}}$ Jornada Científica Da UFSCAR, São Carlos. 2007, Anais. UFSCAR, 3:1634.

CONDE, A.; FIGUEIREDO, B. Ansiedade na Gravidez: Implicações para a saúde e desenvolvimento do bebê e mecanismos neurofisiológicos envolvidos. Acta Pediatr Port, v. 1, n. 36, p. 41-49. 2005.

CORREIA, L.L.; LINHARES, M.B.M. Ansiedade materna nos períodos pré e pós-natal: revisão da literatura. Rev Latino-am Enfermagem. v. 15, n. 4, jul./ago. 2007. 
COUTO, E. R. et al. Qualidade de vida, depressão e ansiedade em gestantes com má história gestacional. São Paulo Med. J. [online], v. 127, n. 4, p. 185-189, 2009.

CRESTANI, A. H. et. al. A experiência da maternidade e a dialogia mãe-filho com distúrbio de linguagem. Rev. CEFAC. v. 14, n. 2, p. 350-360, mar./abril 2012.

CUNHA, J. A. Manual da versão em português das Escalas Beck. São Paulo: Casa do Psicólogo, 2001.

FAISAL-CURY, A., MENEZES, P.R. Ansiedade no puerpério: prevalência e fatores de risco. Rev. Bras. Ginecol. Obstet. v. 28, n. 3, mar. 2006.

FERREIRA, C. L et al. Universidade, contexto ansiogênico? Avaliação de traço e estado de ansiedade em estudantes do ciclo básico. Rev. Ciênc. Saúde Coletiva. Rio de Janeiro, v. 14, n. 3, maio/jun. 2009.

FLORES, M. R; RAMOS, A. P.; MORAES, A., BELTRAMI, L. Associação entre indicadores de risco ao desenvolvimento infantil e estado emocional materno. Rev. CEFAC, n. ahead, p.00-00, 2012. ISSN 1516-1846.

FRIZZO, G. B. et al. Depressão pós-parto: evidências a partir de dois casos clínicos. Psicologia Reflexão Crítica. Porto Alegre, v. 23, n. 1, jan./abr. 2010.

GABBARD, G. O. Psiquiatria psicodinâmica na prática clínica. 4. ed. Porto Alegre: Artmed, 2006.

KUPFER, M. C. M. Pesquisa multicêntrica de indicadores clínicos de risco para o desenvolvimento infantil. 2008. Disponível em: <http://www.fmcsv.org.br/ Pt-br/acervodigital/desenvolvimentodaprimeirainfancia/Paginas/II-WorkshopInternacional---Pesquisa-Multicentrica-de-Indicadores-Cl\%C3\%ADnicos-DI. aspx >. Acesso em: 12 jul. 2010.

KUPFER, M. C. M.; BERNARDINO, L. M. F. As relações entre construção da imagem corporal, função paterna e hiperatividade: reflexões a partir da Pesquisa IRDI. Rev. latinoam. psicopatol. Fundam. São Paulo, v. 12, n.1, mar. 2009.

LEMOS, C. T. G. Los procesos metafóricos y metonímicos como mecanismos de cambio. Substratum, v. 1, n. 1, p.121-135,1992.

LEMOS, M. E. S.; BARROS, C. G. C.; AMORIM, R. H. C. Representações familiares sobre as alterações no desenvolvimento da linguagem de seus filhos. Distúrbios da Comunicação, São Paulo, v. 18, n. 3, p. 323-333, dez. 2006.

LOPES, R. C. S. et al. O antes e o depois: expectativas e experiências de mães sobre o parto. Psicologia Reflexão e Crítica, v. 18, n. 2. p. 247-254, maio/ago. 2005 .

MIAN, L. et al. A depressão materna e o comportamento de crianças em idade escolar. Psicologia: Teoria e Pesquisa, Brasília, v. 25, n. 1, jan./mar. 2009. 
MOTTA, M. G et al. Efeitos da depressão materna no desenvolvimento neurobiológico e psicológico da criança. Revista de Psiquiatria do Rio Grande do Sul, v. 27, n. 2, p. 165-176, maio/ago. 2005

NUNES, S. A. N; FERNANDES M. G., VIEIRA, M. L., Interações sociais precoces: uma análise das mudanças nas funções parentais. Revista Brasileira Crescimento e Desenvolvimento Humano, 17, n. 3, dez. 2007.

PINTO, I. D. et al. Ansiedade e depressão materna e relatos sobre o bebê prematuro. Psicologia: Teoria e Pesquisa, Brasília, v. 25, n. 1, jan./mar. 2009.

PRADO, A. B, PIOVANOTTI, M. R. A., VIEIRA, M. L. Concepções de pais e mães sobre comportamento paterno real e ideal. Revista Psicologia em Estudo, Maringá, v. 12, n.1, p. 54-64, 2007. Disponível em: <http://www.scielo.br/pdf/pe/ v12n1/v12n1a05.pdf>. Acesso em: 16 maio 2010.

PRETTO-CARLESSO, J.; SOUZA, A. P. R. Dialogia Mãe-Filho em Contextos de Depressão Materna: revisão de Literatura. Rev.CEFAC, v. 13, n. 6, p. 11191126, 2011.

RECHIA, I. C. et al. Processos de substituição e variabilidade articulatória na fala de sujeitos com dispraxia verbal. Revista Sociedade Brasileira de Fonoaudiologia, v. 14, n. 4, p. 547-552, 2009.

RECHIA, I. C. et al. Processos de apagamento na fala de sujeitos com dispraxia verbal. Revista CEFAC, v. 12, n 3, p. 421-426, jun. 2010.

SILVA, E. T. S.; BOTTI, N. C. L. Depressão puerperal - uma revisão de literatura. Revista Eletrônica de Enfermagem, v. 07, n. 02, p. 231-238, 2005. Disponível em: <http://www.revistas.ufg.br/index.php/fen/article/view/880>. Acesso em: 13 jun. 2010.

SOUZA, A. P. F. R. et al. A entrevista continuada na clínica de linguagem infantil. Fractal: Revista de Psicologia, v. 21, n. 3, p. 601-612, set./dez. 2009.

WINNICOTT, D.W. Da pediatria à psicanálise: obras escolhidas. Rio de Janeiro: Imago, 2000.

ZUCCHI, M. Depressão na gravidez e prematuridade. Aspectos epistemológicos da investigação. Cadernos de Saúde Pública, Rio de Janeiro, v. 15, n. 1, p. 89-97, jan./mar. 1999.

Recebido em: 20 de agosto de 2010

Aceito em: 05 de junho de 2013 